\title{
Brain GABA Levels Are Associated with Inhibitory Control Deficits in Older Adults
}

\author{
닐e Hermans, ${ }^{1}$ Inge Leunissen, ${ }^{1}$ Lisa Pauwels, ${ }^{1}$ Koen Cuypers, ${ }^{1}$ Ronald Peeters, ${ }^{2}$ Nicolaas A.J. Puts, ${ }^{3,4}$ \\ Richard A.E. Edden, ${ }^{3,4}$ and ${ }^{-S t e p h a n ~ P . ~ S w i n n e n ~}{ }^{1,5}$ \\ ${ }^{1}$ Movement Control and Neuroplasticity Research Group, Department of Movement Sciences, Group Biomedical Sciences, KU Leuven, 3001 Leuven, \\ Belgium, ${ }^{2}$ Department of Imaging \& Pathology, Group Biomedical Sciences, KU Leuven, 3000 Leuven, Belgium, ${ }^{3}$ F.M. Kirby Research Center for Functional \\ Brain Imaging, Kennedy Krieger Institute, Baltimore, Maryland 21205, ${ }^{4}$ Russell H. Morgan Department of Radiology and Radiological Science, Johns \\ Hopkins School of Medicine, Baltimore, Maryland 21205, and ${ }^{5}$ Leuven Brain Institute (LBI), 3000 Leuven, Belgium
}

Healthy aging is accompanied by motor inhibition deficits that involve a slower process of stopping a prepotent motor response (i.e., reactive inhibition) rather than a diminished ability to anticipate stopping (i.e., proactive inhibition). Some studies suggest that efficient motor inhibition is related to GABAergic function. Since age-related alterations in the GABA system have also been reported, motor inhibition impairments might be linked to GABAergic alterations in the cortico-subcortical network that mediates motor inhibition. Thirty young human adults (mean age, 23.2 years; age range, 18 -34 years; 14 men) and 29 older human adults (mean age, 67.5 years; age range, 60-74 years; 13 men) performed a stop-signal task with varying levels of stop-signal probability. GABA ${ }^{+}$levels were measured with magnetic resonance spectroscopy (MRS) in right inferior frontal cortex, pre-supplementary motor area (pre-SMA), left sensorimotor cortex, bilateral striatum, and occipital cortex. We found that reactive inhibition was worse in older adults compared with young adults, as indicated by longer stop-signal reaction times (SSRTs). No group differences in proactive inhibition were observed as both groups slowed down their response to a similar degree with increasing stop-signal probability. The MRS results showed that tissuecorrected $\mathrm{GABA}^{+}$levels were on average lower in older as compared with young adults. Moreover, older adults with lower $\mathrm{GABA}^{+}$levels in the pre-SMA were slower at stopping (i.e., had longer SSRTs). These findings suggest a role for the GABA system in reactive inhibition deficits.

Key words: GABA; healthy aging; magnetic resonance spectroscopy; proactive inhibition; reactive inhibition

Significance Statement

Inhibitory control has been shown to diminish as a consequence of aging. We investigated whether the ability to stop a prepotent motor response and the ability to prepare to stop were related to GABA levels in different regions of the network that was previously identified to mediate inhibitory control. Overall, we found lower GABA levels in older adults compared with young adults. Importantly, those older adults who were slower at stopping had less GABA in the pre-supplementary motor area, a key node of the inhibitory control network. We propose that deficits in the stop process in part depend on the integrity of the GABA system.

\section{Introduction}

The ability to inhibit inappropriate actions is important for adaptive behavior. In some situations, we need to quickly cancel an

Received March 22, 2018; revised July 6, 2018; accepted July 24, 2018.

Author contributions: L.H., I.L., K.C., R.P., N.A.J.P., R.A.E.E., and S.P.S. designed research; L.H., I.L., and K.C. performed research; N.A.J.P. and R.A.E.E. contributed unpublished reagents/analytic tools; L.H. and I.L. analyzed data; L.H., I.L., L.P., K.C., N.A.J.P., R.A.E.E., and S.P.S. wrote the paper.

S.P.S. is supported by Research Foundation Flanders Grants G0708.14 and G089818N, Excellence of Science Grant 30446199 (MEMODYN), and KU Leuven Research Fund Grant C16/15/070. This study applies tools developed under National Institutes of Health (NIH) Grants R01-EB-016089, R01-023963, and P41-EB015909; R.A.E.E. also receives salary support from these grants. N.A.J.P. receives salary support from NIH Grant K99-MH-107719. We thank René Clerckx for help with construction of the experimental setup. already initiated action in response to an external cue, such as stopping yourself from crossing the road when suddenly a car comes around the corner; this is called reactive inhibition. However, often it is possible to anticipate the potential need for inhibiting a motor action. For example, when driving close to a school, one might expect children to cross the street. This leads us to slow

The authors declare no competing financial interests.

Correspondence should be addressed to Stephan P. Swinnen, Movement Control and Neuroplasticity Research Group, Group Biomedical Sciences, KU Leuven, Tervuursevest 101, B-3001 Heverlee, Belgium. E-mail: stephan.swinnen@kuleuven.be.

DOI:10.1523/JNEUROSCI.0760-18.2018

Copyright $\odot 2018$ the authors $\quad 0270-6474 / 18 / 387844-08 \$ 15.00 / 0$ 


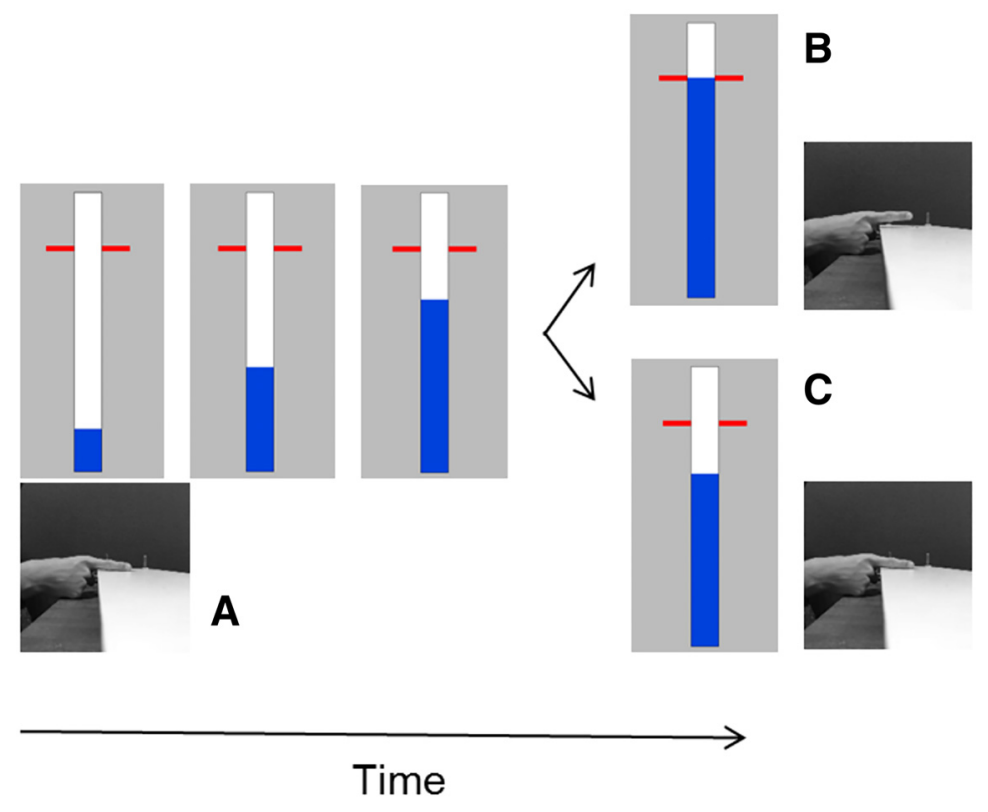

Figure 1. Stop-signal task. $A$, Participants had to rest their right index finger on a switch. On a computer screen, a bar started to fill at a constant and equal rate, crossing a red horizontal target line at $800 \mathrm{~ms}$. The color of the bar was light blue, dark blue, or magenta for the $0 \%, 20 \%$ and $40 \%$ stop-signal probability, respectively. $\boldsymbol{B}$, In go trials, participants had to stop the indicator as close as possible to the red target. The bar could be stopped by lifting the finger/releasing the switch. $\boldsymbol{C}$, In stop trials, the bar would stop filling before it reached the target line. Participants had to cancel the movement of lifting their finger/releasing the switch.

down and prepare to stop in time if the need arises, which is called "proactive inhibition." Evidence indicates that healthy aging results in difficulties in reactive inhibition, whereas proactive inhibition remains intact (Smittenaar et al., 2015; Bloemendaal et al., 2016; Kleerekooper et al., 2016).

Successful motor inhibition is mediated by a cortico-subcortical network (Aron, 2011; Jahanshahi et al., 2015). The right inferior frontal cortex (RIFC), pre-supplementary motor area (preSMA), and subthalamic nucleus (STN) are recruited during reactive inhibition (Aron and Poldrack, 2006; Aron, 2007), whereas proactive inhibition is thought to rely more heavily on the striatum (Aron, 2011; Leunissen et al., 2016). When an external cue signals the need for inhibiting a prepotent motor response, the frontal regions of this network generate a stop command to intercept the planned movement that is generated in the primary motor cortex (M1). Transcranial magnetic stimulation (TMS) studies have shown that successful cancelation of movement is associated with active suppression of M1 activity (Wessel et al., 2013) mediated by GABA receptors (Coxon et al., 2006; van den Wildenberg et al., 2010). However, it is difficult to assess cortical GABAergic functioning other than M1 with TMS, and especially subcortical regions require other techniques such as magnetic resonance spectroscopy (MRS), to probe the GABA system.

The use of spectral editing techniques in MRS allows the differentiation of the GABA signal from more highly concentrated overlapping signals of other brain metabolites by selectively manipulating the GABA signal in half of the transients of the acquisition, but not in the other half. The difference spectrum then contains only those manipulated signals, resulting in a GABAedited spectrum (Puts and Edden, 2012; Mullins et al., 2014). MRS studies in young adults have shown that GABA levels in the striatum and anterior cingulate cortex are correlated with interindividual differences in go-no-go task performance (Silveri et al., 2013; Quetscher et al., 2015), suggesting that motor inhibition efficiency depends on GABAergic functioning within the corticosubcortical network.
Emerging evidence suggests that the GABA system is altered in healthy aging. Several TMS studies have shown that the modulation of intracortical inhibition in M1 during motor performance is diminished in older adults (Levin et al., 2014). Using MRS, an age-related decrease in GABA levels has initially been observed in frontal and parietal regions (Gao et al., 2013; Porges et al., 2017a). However, a recent study (Porges et al., 2017b) reported that age-related declines in GABA levels may also depend on the applied tissue correction. More specifically, when accounting for the unequal distribution of GABA within gray matter (GM) and white matter (WM) and the amount of atrophy in the different tissues, no age-related effect was observed. Nevertheless, GABA levels within frontal regions were predictive for global cognitive performance, independent of tissue correction (Porges et al., 2017b). Despite evidence for a role of GABA in motor inhibition, no study has yet investigated GABA levels within the cortico-subcortical network and their agerelated implications for motor inhibition.

Here, younger and older adults performed a stop-signal task, with varying levels of stop-signal probability (SSP) to assess reactive and proactive inhibition. GABA levels in the RIFC, pre-SMA, left sensorimotor cortex (LSM1), bilateral striatum, and occipital cortex (OCC) were measured using edited MRS of GABA. We hypothesized that reactive inhibition would be less efficient in older, compared with younger, adults, whereas the degree of proactive inhibition would be similar across groups. Based on prior imaging and TMS evidence (Coxon et al., 2006; Aron, 2011), we hypothesized that reactive inhibition efficiency would correlate with GABA levels within the RIFC, pre-SMA, and LSM1, whereas the amount of proactive inhibition would correlate with GABA levels in the striatum. We hypothesized that lower GABA levels would be related to worse motor inhibition (Silveri et al., 2013; Quetscher et al., 2015).

\section{Materials and Methods}

Participants. A total of 30 healthy young adults (14 men; mean age \pm SD, $23.2 \pm 4.3$ years; age range, $18.3-33.8$ years) and 29 healthy older adults ( 13 men; mean age $\pm \mathrm{SD}, 67.5 \pm 3.9$ years; age range, $60.2-73.8$ years) participated in this study. All participants were right handed according to the Oldfield Handedness Scale (laterality quotient: mean \pm SD, $91 \pm 12$; range, 57-100; number missing, 4), and none reported a history of psychiatric or neurological disorders. There were five young adults who completed only the MRS session, due to early dropout. The experiment was approved by the local Ethics Committee for Biomedical Research (approval \#s58333), and all participants gave written informed consent.

Stop-signal task. An anticipated response version of the stop-signal task (Fig. 1) was used to investigate reactive and proactive inhibition (Coxon et al., 2007; Zandbelt and Vink, 2010). Participants were instructed to rest their right index finger on a switch (operating force, 0.10 $\mathrm{N}$; catalog \#V-7-2B17D8-162, Honeywell). A vertical indicator (Fig. 1, blue bar) was shown on a computer screen (refresh rate, $60 \mathrm{~Hz}$ ), which moved upward at a constant speed on each trial, crossing a horizontal target line at $800 \mathrm{~ms}$ from onset. The main task was to stop the indicator as close as possible to the target line by lifting the right index finger from the switch (i.e., go trials). Participants received feedback with respect to performance on go trials. More specifically, the color of the target line 
changed after each go trial as a function of task performance (green, yellow, orange, or red for responses within $20,40,60$, or $>60 \mathrm{~ms}$ from the target line, respectively). In some trials (i.e., stop trials), the indicator stopped before reaching the target line, and participants were instructed to cancel the movement of lifting their finger/releasing the switch. A dynamic staircase algorithm was used to adjust the time that the indicator stopped (i.e., the stop time) ensuring equal numbers of successful and unsuccessful stop trials (i.e., $P$ (inhibit) $\sim 50 \%$ ). More specifically, the stop time increased by $33 \mathrm{~ms}$ after a successful stop trial, whereas it decreased by $33 \mathrm{~ms}$ after an unsuccessful stop trial. To investigate proactive inhibition, the SSP was manipulated and stop trials occurred in $0 \%$, $20 \%$, or $40 \%$ of all trials. The color of the indicator was light blue for the $0 \%$ SSP condition, dark blue for the $20 \%$ SSP condition, and magenta for the $40 \%$ SSP condition. The $0 \%$ SSP condition was presented in the first block, which consisted of 25 trials. Next, the $20 \%$ and $40 \%$ SSP conditions were randomly presented within the second block, which consisted of 150 trials with a matching number of stop trials across the conditions ( 80 go trials and 20 stop trials for the $20 \%$ SSP condition; 30 go trials and 20 stop trials for the $40 \%$ SSP condition). The intertrial interval was set to $3.25 \mathrm{~s}$, and the indicator was set to empty $1.28 \mathrm{~s}$ after trial onset in each block. Participants performed the task twice on separate days, resulting in a total of 350 trials. All participants performed three practice blocks on the first day: one with $0 \%$ SSP (20 trials), one with $30 \%$ SSP ( 35 trials), and one with both $20 \%$ and $40 \%$ SSP ( 35 trials).

We instructed participants to perform the task as accurately as possible (aim for green or yellow lines after go trials) and that it would not be possible to cancel the movement of lifting their finger on all stop trials. Furthermore, the participants were told that no stops would occur when the indicator was light blue and that the probability of stops was higher when the indicator was magenta compared with dark blue. After the practice blocks, participants were asked to describe the difference between the colors to make sure that the instructions were understood correctly.

Behavioral data analysis. Behavioral data analysis was performed for the $2 \mathrm{~d}$ separately, and the results were averaged across days. The response time on go trials (GoRT) was measured as the time between the start of the trial and the moment when the finger was lifted from the switch. A GoRT of $800 \mathrm{~ms}$ reflects a perfectly timed response. Go trials with early response times $(<400 \mathrm{~ms})$ or no response $(>1280 \mathrm{~ms})$ were removed. To validate the assumptions of the horse race model (Logan and Cowan, 1984), we checked whether the average response time was shorter on failed stop trials than go trials for each participant separately and for each age group (paired $t$ test; SPSS Statistics 24, IBM; RRID:SCR_002865). As a measure of reactive inhibition, the stop-signal reaction time (SSRT) was calculated across the $20 \%$ and $40 \%$ SSP conditions using the integration method (Verbruggen and Logan, 2009). More specifically, the number of failed stop trials was divided by the total number of stop trials to get $P$ (respond). Next, GoRTs were sorted in ascending order, and the $n$th GoRT was obtained where $n$ equals the number of go trials multiplied by $P$ (respond) (Verbruggen and Logan, 2009). The SSRT was estimated by subtracting the average stop time from the $n$th GoRT.

MRI acquisition. Scanning was performed on a Philips $3 \mathrm{~T}$ Achieva Dstream System ([Philips Healthcare]) with a 32-channel receiver head coil. A high-resolution 3D T1-weighted structural image [3D turbo field echo (TFE); repetition time $(\mathrm{TR})=9.6 \mathrm{~ms}$; echo time $(\mathrm{TE})=4.6 \mathrm{~ms}$; $0.98 \times 0.98 \times 1.2 \mathrm{~mm}^{3} ; 185$ coronal slices] and two short 3D T1weighted structural images $(3 \mathrm{D} \mathrm{TFE}$; TR $=9.6 \mathrm{~ms}$; TE $=4.6 \mathrm{~ms} ; 1.2 \times$ $1.2 \times 2 \mathrm{~mm}^{3}$; 111 coronal slices) were acquired. GABA-edited MRS data were acquired using the MEGA-PRESS spectral editing method (Mescher et al., 1998) and the following acquisition parameters: 14 ms editing pulses at $7.46 \mathrm{ppm}$ (edit-OFF) and $1.9 \mathrm{ppm}$ (edit-ON); TE $=68 \mathrm{~ms}$; TR $=2 \mathrm{~s} ; 320$ averages; $2 \mathrm{kHz}$ spectral width; MOIST (multiple optimizations insensitive suppression train) water suppression for a total acquisition time of $11 \mathrm{~min}$ (i.e., the "Big GABA" protocol; Mikkelsen et al., 2017). A total of 16 additional water-unsuppressed averages were acquired in an interleaved manner from all voxels (Edden et al., 2016). The editing scheme results in a $3 \mathrm{ppm}$ signal that contains a substantial $(\sim 50 \%)$ contribution from coedited macromolecules (Rothman et al., 1993; Harris et al., 2015b; Mikkelsen et al., 2016) in addition to the targeted GABA signal. Therefore, all GABA values are reported as $\mathrm{GABA}^{+}$(i.e., GABA + macromolecules).

Voxels of interest were planned in the LSM1 $\left(3 \times 3 \times 3 \mathrm{~cm}^{3}\right)$, bilateral pre-SMA $\left(3 \times 3 \times 3 \mathrm{~cm}^{3}\right)$, RIFC $\left(4 \times 2.5 \times 2.5 \mathrm{~cm}^{3}\right)$, bilateral striatum [left striatum (LSTR)/right STR (RSTR), $3 \times 3 \times 3 \mathrm{~cm}^{3}$ ], and bilateral OCC $\left(3 \times 3 \times 3 \mathrm{~cm}^{3}\right.$; control region $)$. The imaging protocol started with the long high-resolution T1 scan followed by three MRS scans. After a short break outside the scanner, a short $\mathrm{T} 1 \mathrm{scan}$ was acquired followed by two MRS scans, a short T1 scan, and an MRS scan. All regions were acquired in a random order, except that the LSTR was followed by the RSTR or vice versa. The T1-weighted images were used to position the voxels according to anatomical landmarks (Fig. 2, representative voxel positions). The LSM1 voxel was centered over the left-hand knob (Yousry et al., 1997) with one surface parallel to the cortical surface in the coronal and axial views (Puts et al., 2011). For the pre-SMA voxel, a horizontal line was drawn between the anterior commisure (AC) and the posterior commissure in the sagittal plane, and a perpendicular line was constructed to this line through the AC. The pre-SMA voxel was centered over the median line with the posterior superior corner intersecting the perpendicular line (Behrens et al., 2006; Kim et al., 2010). Subsequently, it was aligned with the cortical surface in the sagittal view. The RIFC voxel was positioned above the temporal lobe and centered over the inferior frontal gyrus, with the longest axis extending anterior to posterior, parallel to the cortical surface. The STR voxels were centered over the putamen. In the coronal and axial view, we checked that the voxel was not positioned in the ventricle, and, as a consequence, only part of the caudate was covered. The OCC voxel was centered on the median line, positioned as posterior as possible and aligned with the cerebellar tentorium in the sagittal plane (Puts et al., 2011).

MRS analysis. MRS spectra were analyzed using Gannet 3.0 (Gannet; RRID:SCR_016049) and Matlab 2016b (RRID:SCR_001622; Edden et al., 2014). All individual frequency domain spectra were frequency and phase corrected using spectral registration (Near et al., 2015), filtered with a $3 \mathrm{~Hz}$ exponential line broadening and zero filled. The difference spectrum was fitted between 2.79 and $4.10 \mathrm{ppm}$ using a three-Gaussian function with a nonlinear baseline to estimate $\mathrm{GABA}^{+}$at $3.0 \mathrm{ppm}$. Water was modeled with a Gaussian-Lorentzian model. All short T1-weighted images were coregistered to the long high-resolution T1-weighted image using a rigid transformation with 6 df (SPM 12; RRID:SCR_007037). Subsequently, each voxel was coregistered to the (coregistered) T1weighted image that was used to position the voxel. The resulting voxels in the long T1 image space were segmented, and the different tissue fractions of the voxels were obtained (GM, WM, and CSF). GABA ${ }^{+}$ levels were calculated relative to water and corrected for tissue-related factors with the assumption that $\mathrm{GABA}^{+}$levels are twice as high in GM compared with WM, according to the study by Harris et al. (2015a). Subsequently, $\mathrm{GABA}^{+}$levels were normalized to the average voxel composition separately for each age group (i.e., young or older age group; Harris et al., 2015a, their Eq. 6). Quantitative data quality metrics were measured for each voxel (Mikkelsen et al., 2017), including fit errors of the $\mathrm{GABA}^{+}$peak, $N$-acetylaspartate (NAA), and GABA ${ }^{+}$signal-to-noise ratios (SNRs), and the SD of the water frequency offset (FreqStdevHz), which is an indication of frequency drift and motion. A total of 44 of 354 spectra were excluded due to high-fit errors (young, $N=8$; older, $N=7$; range fit errors, 13-68\%) or poor data quality (insufficient water suppression/lipid contamination: young, $N=11$; older, $N=18$ ). Table 1 shows a summary of the data quality measures of the spectra that were included after visual inspection. Age-related differences in data quality of the remaining spectra were tested with a Student's $t$ test.

Experimental design and statistical analyses. The effect of age on $P$ (inhibit), stop time, and the GoRT difference $\left(\right.$ GoRT $\left._{40-20}\right)$ score was tested with Student's $t$ tests. Group differences in reactive inhibition were tested with a Student's $t$ test with SSRT across the $20 \%$ and $40 \%$ SSP conditions as dependent variable. Group differences in proactive inhibition were tested with a 2 (age group, young/older) $\times 3$ (SSP condition, $0 \% / 20 \% /$ $40 \%)$ ANOVA with GoRT as the dependent variable. GoRTs were expected to increase as a function of SSP when participants proactively prepared to stop. When the assumption of sphericity was violated, a Greenhouse-Geisser correction was used. 

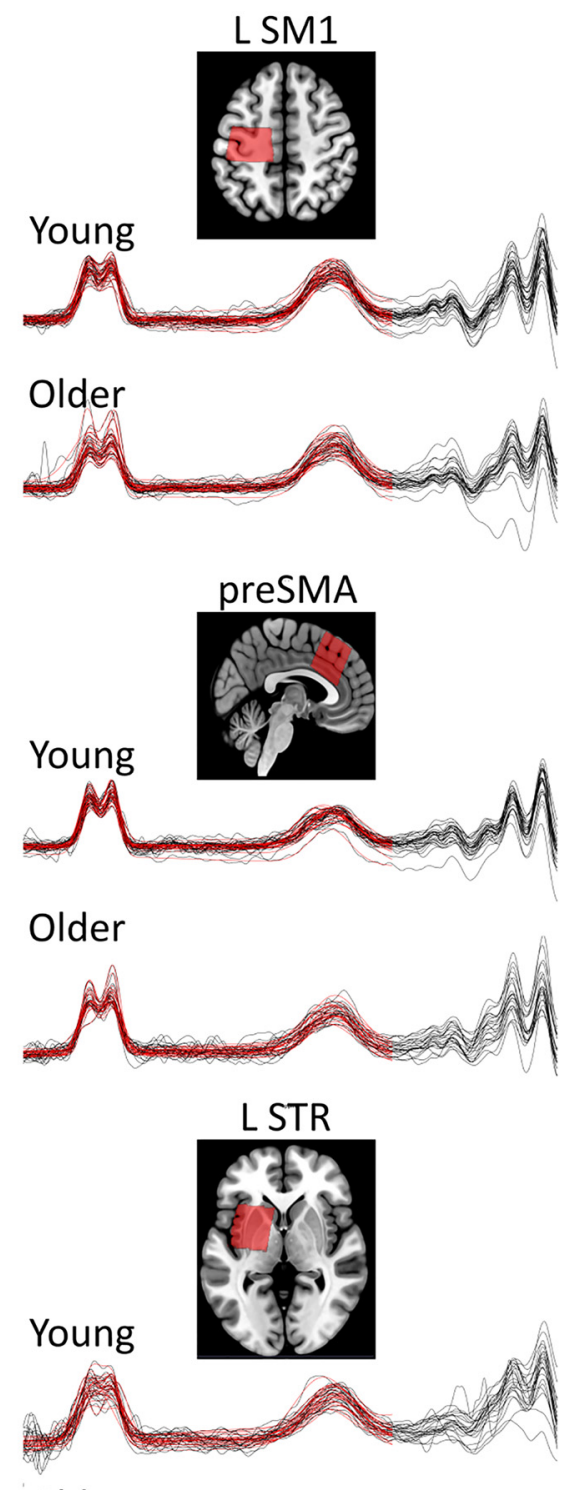

Older

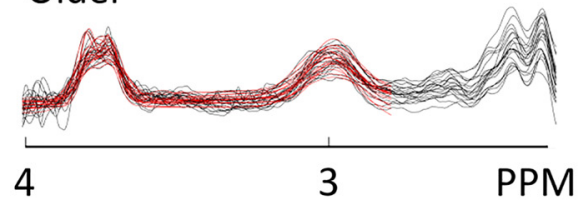

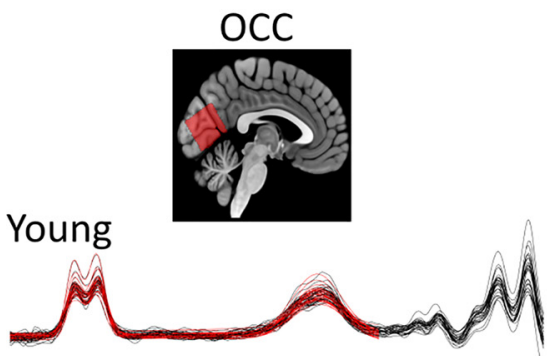

Older
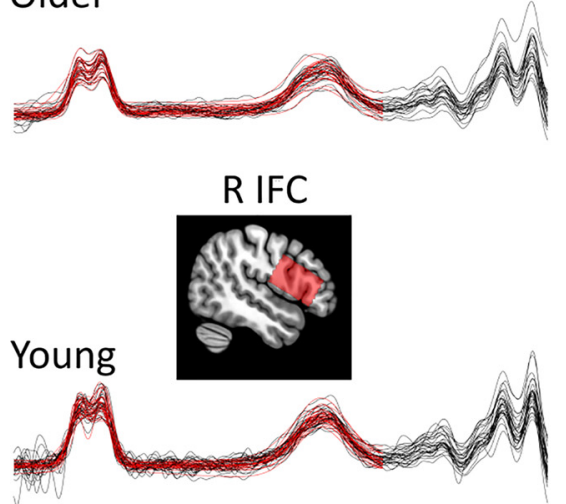

Older
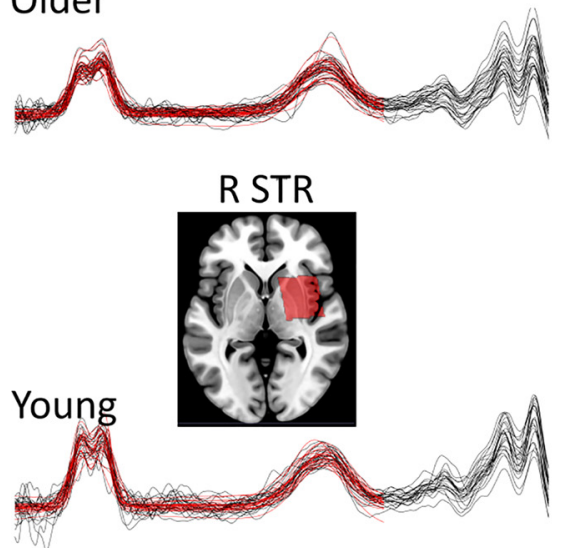

Older

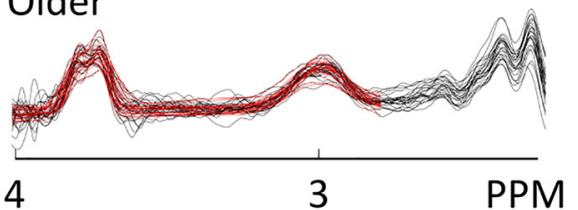

Figure 2. Example voxel positions (coregistered to $\mathrm{T} 1$ ) and spectra from all participants with fitting results (i.e., red lines). The GABA ${ }^{+}$peak is visible at 3 ppm.

To investigate group differences in tissue-corrected $\mathrm{GABA}^{+}$levels, a mixed model was used with age group and brain region as fixed factors and participant as a random factor (JMP Pro 12, SAS Institute; RRID: SCR_014242). Additionally, we performed a secondary analysis and added FreqStdevHz and NAA SNR to the mixed model to control for the possible effect of data quality on measured $\mathrm{GABA}^{+}$levels. Previously, an association was found between $\mathrm{GABA}^{+}$levels and frequency offset (Mikkelsen et al., 2017).

Pearson correlation analyses were performed to investigate the relationship between tissue-corrected $\mathrm{GABA}^{+}$levels and reactive/proactive inhibition in young and older adults separately. SSRT was used as a measure of reactive inhibition, whereas the difference in GoRT between the $40 \%$ and $20 \%$ SSP conditions $\left(\mathrm{GoRT}_{40-20}=\mathrm{GoRT}_{40}-\mathrm{GoRT}_{20}\right)$ was used as a measure of proactive inhibition. Participants who proactively prepare to stop by slowing down as a function of SSP will have a positive GoRT difference score. These two behavioral measures were correlated with GABA ${ }^{+}$levels in LSM1, OCC, pre-SMA, RIFC, LSTR, and RSTR. The significance level was set at $p<0.05$ for all tests, and data are presented as the mean \pm SD in the text.

\section{Results}

Stop-signal task

The percentage of GoRT errors across all SSP conditions was low in young (early GoRT, $0 \%$; no response, $0.55 \pm 1.52 \%$ ) and older adults (early GoRT, $0.16 \pm 0.54 \%$; no response, $0.45 \pm 0.96 \%$ ). The average GoRT on failed stop trials was lower than the average GoRT for each participant. Moreover, a paired $t$ test indicated that this difference in GoRT was significant in both young adults $\left.t_{(24)}=-12.738, p<0.001\right)$ and older adults $\left(t_{(28)}=-12.959\right.$, $p<0.001$ ), which is consistent with the assumptions of the horse race model (Logan and Cowan, 1984). The $P$ (inhibit) value was 
Table 1. Data quality metrics for the tissue-corrected $\mathrm{GABA}^{+}$levels and segmentation results

\begin{tabular}{|c|c|c|c|c|c|c|c|c|c|}
\hline \multirow[b]{2}{*}{ Region } & \multirow[b]{2}{*}{ Group } & \multirow[b]{2}{*}{$N$} & \multicolumn{4}{|c|}{ Data quality metrics } & \multicolumn{3}{|c|}{ Tissue segmentations } \\
\hline & & & Fit error (\%) & NAA SNR & GABA SNR & FreqStDevHz & GM & WM & CSF \\
\hline \multirow[t]{3}{*}{ LSM1 } & Young & 30 & $4.11 \pm 1.25$ & $392 \pm 74$ & $28 \pm 4$ & $0.46 \pm 0.28$ & $0.34 \pm 0.03$ & $0.60 \pm 0.04$ & $0.06 \pm 0.02$ \\
\hline & Older & 27 & $4.44 \pm 1.60$ & $296 \pm 88$ & $23 \pm 4$ & $0.73 \pm 0.29$ & $0.26 \pm 0.03$ & $0.62 \pm 0.04$ & $0.12 \pm 0.03$ \\
\hline & $p$ value & & 0.395 & $<0.001$ & $<0.001$ & 0.001 & $<0.001$ & 0.052 & $<0.001$ \\
\hline \multirow[t]{3}{*}{ Pre-SMA } & Young & 27 & $7.04 \pm 1.60$ & $406 \pm 58$ & $27 \pm 5$ & $0.51 \pm 0.32$ & $0.53 \pm 0.03$ & $0.32 \pm 0.04$ & $0.15 \pm 0.03$ \\
\hline & Older & 22 & $7.10 \pm 2.07$ & $307 \pm 65$ & $23 \pm 4$ & $0.69 \pm 0.24$ & $0.45 \pm 0.03$ & $0.32 \pm 0.04$ & $0.23 \pm 0.04$ \\
\hline & $p$ value & & 0.903 & $<0.001$ & 0.001 & 0.038 & $<0.001$ & 0.707 & $<0.001$ \\
\hline \multirow[t]{3}{*}{ RIFC } & Young & 29 & $5.32 \pm 1.47$ & $304 \pm 44$ & $21 \pm 4$ & $0.57 \pm 0.29$ & $0.56 \pm 0.04$ & $0.37 \pm 0.05$ & $0.08 \pm 0.03$ \\
\hline & Older & 29 & $5.25 \pm 1.53$ & $264 \pm 47$ & $20 \pm 4$ & $0.96 \pm 0.43$ & $0.47 \pm 0.04$ & $0.40 \pm 0.05$ & $0.13 \pm 0.04$ \\
\hline & $p$ value & & 0.848 & 0.001 & 0.444 & $<0.001$ & $<0.001$ & 0.010 & $<0.001$ \\
\hline \multirow[t]{3}{*}{ LSTR } & Young & 22 & $6.61 \pm 1.83$ & $225 \pm 38$ & $19 \pm 4$ & $0.80 \pm 0.55$ & $0.58 \pm 0.03$ & $0.35 \pm 0.03$ & $0.08 \pm 0.01$ \\
\hline & Older & 21 & $6.76 \pm 1.90$ & $198 \pm 36$ & $16 \pm 4$ & $1.06 \pm 0.53$ & $0.51 \pm 0.03$ & $0.35 \pm 0.04$ & $0.14 \pm 0.03$ \\
\hline & $p$ value & & 0.796 & 0.021 & 0.005 & 0.131 & $<0.001$ & 0.770 & $<0.001$ \\
\hline \multirow[t]{3}{*}{ RSTR } & Young & 23 & $7.10 \pm 2.26$ & $263 \pm 46$ & $19 \pm 4$ & $0.64 \pm 0.42$ & $0.58 \pm 0.03$ & $0.33 \pm 0.03$ & $0.09 \pm 0.01$ \\
\hline & Older & 25 & $7.13 \pm 1.89$ & $212 \pm 23$ & $17 \pm 3$ & $1.02 \pm 0.44$ & $0.51 \pm 0.03$ & $0.34 \pm 0.04$ & $0.15 \pm 0.03$ \\
\hline & $p$ value & & 0.966 & $<0.001$ & 0.012 & 0.004 & $<0.001$ & 0.827 & $<0.001$ \\
\hline \multirow[t]{3}{*}{$\mathrm{OCC}$} & Young & 30 & $4.27 \pm 0.80$ & $375 \pm 67$ & $23 \pm 4$ & $0.53 \pm 0.31$ & $0.66 \pm 0.04$ & $0.26 \pm 0.04$ & $0.08 \pm 0.02$ \\
\hline & Older & 25 & $5.30 \pm 1.31$ & $294 \pm 61$ & $18 \pm 4$ & $0.90 \pm 0.44$ & $0.56 \pm 0.04$ & $0.30 \pm 0.03$ & $0.14 \pm 0.03$ \\
\hline & $p$ value & & 0.001 & $<0.001$ & $<0.001$ & $<0.001$ & $<0.001$ & $<0.001$ & $<0.001$ \\
\hline
\end{tabular}

Data are shown as the mean \pm SD.

close to $50 \%$ in young adults $(52.6 \pm 1.0)$ and older adults $(52.5 \pm 1.1)$ and did not significantly differ between groups $\left(t_{(52)}=0.499, p=0.620\right)$. Furthermore, there was no effect of age on stop time (young, $616 \pm 14$; older, $609 \pm 23 ; t_{(46.655)}$ $=1.511, p=0.138)$.

We found an age effect on SSRT with longer SSRTs in older adults (young, $193 \pm 12$; older, $206 \pm 17 ; t_{(52)}=-2.998$, $p=0.004)$. There was no age effect on overall GoRT $\left(F_{(1,52)}=2.177, p=0.146\right)$. However, both young and older adults showed a significant increase in GoRT as a function of SSP (young: $\mathrm{GoRT}_{0}, 802 \pm 10$; $\mathrm{GoRT}_{20}, 813 \pm 9$; $\mathrm{GoT}_{40}, 823 \pm 11$; older: $\mathrm{GoRT}_{0}, 806 \pm 17$ GoRT $_{20}, 818 \pm 19$; $\mathrm{GoRT}_{40}, 832 \pm 24 ; F_{(1.727,89.798)}=92.882$, $p<0.001)$. Moreover, the interaction between age group and SSP was not significant, indicating that the effect of SSP on GoRT was similar in both groups $\left(F_{(1.727,89.798)}=0.907, p=0.395\right)$. Also, the GoRT difference score $\left(\mathrm{GoRT}_{40-20}\right)$ did not significantly differ between young and older adults (young, $10 \pm 6$; older, $14 \pm 16$; $t_{(37.014)}=$ $-1.061, p=0.269)$. Together, our results indicate that reactive inhibition efficiency was worse in older compared with young adults while proactive inhibition was intact.

\section{MRS}

A mixed model was used to investigate group differences in tissue-corrected $\mathrm{GABA}^{+}$levels. There was a significant main effect of age group $\left(F_{(1,55.9)}=10.912, p=0.002\right)$ and brain region $\left(F_{(5,251.7)}=5.963, p<0.001\right)$. The interaction between age group and brain region was not significant $\left(F_{(5,251.7)}=1.784, p=\right.$ 0.117 ), indicating an overall decline in $\mathrm{GABA}^{+}$levels across brain regions with aging (Fig. 3).

Group analysis of the data quality metrics (Table 1) showed that there was no effect of age on the fit error of the GABA ${ }^{+}$peak (all $p$ values $\geq 0.395$ ) except in the OCC voxel $\left(t_{(53)}=-3.723\right.$, $p<0.001)$. The NAA SNR was significantly higher in older than in young adults (all $p \leq 0.021$ ). Last, the FreqStdevHz value was significantly higher in older than in young adults in all voxels (all $p \leq 0.038)$ except for the $\left(t_{(41)}=-1.544, p=0.131\right)$. This likely indicates that there was more motion in older adults.

A secondary analysis was performed using a mixed model with NAA SNR and FreqStDevHZ as fixed factors of no interest to control for group differences in data quality metrics (Mikkelsen et al., 2017). Importantly, the inclusion of these metrics did not influence the primary results. There was a significant effect of age group $\left(F_{(1,81.6)}=9.737, p=0.003\right)$ and brain region $\left(F_{(5,259.8)}=\right.$ $4.715, p<0.001)$ on tissue-corrected $\mathrm{GABA}^{+}$levels. The interaction between age group and brain region was not significant $\left(F_{(5,251.8)}=1.772, p=0.119\right)$. Finally, $\operatorname{NAA} \operatorname{SNR}\left(F_{(1,293)}=\right.$ $0.313, p=0.576)$ and FreqStDevHz $\left(F_{(1,132.6)}=0.170, p=0.681\right)$ were not associated with tissue-corrected $\mathrm{GABA}^{+}$levels in these cohorts. Post hoc pairwise comparisons with Tukey's test HSD 


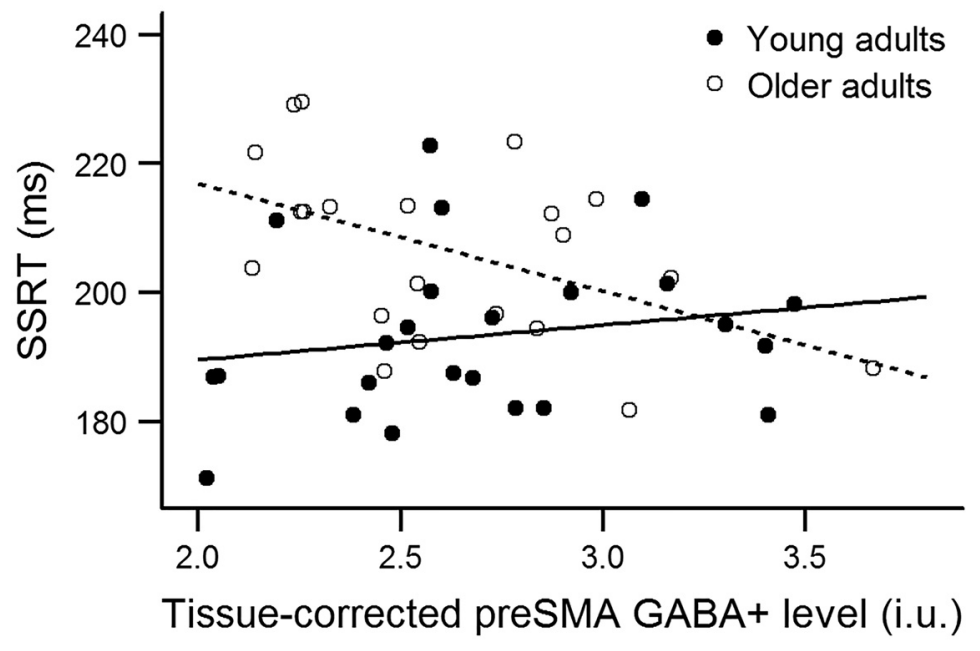

Figure 4. Relationship between SSRT, a measure of reactive inhibition efficiency, and tissue-corrected pre-SMA GABA ${ }^{+}$levels in young adults $(r=0.185, n=24, p=0.387)$ and older adults $(r=-0.459, n=22, p=0.031)$. Lower SSRT values reflect better performance.

were used to explore the effect of brain region on $\mathrm{GABA}^{+}$levels and showed that GABA ${ }^{+}$levels were significantly different between LSM1 and LSTR $(p=0.026)$, LSM1 and RSTR $(p=$ $0.011)$, LSM1 and OCC ( $p=0.001)$, and LSM1 and pre-SMA ( $p=0.007$; all other $p$ values $\geq 0.308$ ), which is suggestive of regional differences in $\mathrm{GABA}^{+}$levels even after tissue correction and normalization.

\section{Behavior and MRS}

As shown in Figure 4, SSRT significantly correlated with tissuecorrected pre-SMA $\mathrm{GABA}^{+}$levels in older adults $\left(r_{(20)}=\right.$ $-0.459, p=0.031)$. Older adults who demonstrated less proficient reactive inhibition, as indicated by a slower inhibitory process (i.e., longer SSRTs), had less $\mathrm{GABA}^{+}$in the pre-SMA. The observed correlation cannot be explained by individual differences in tissue fractions since these did not correlate with SSRT (GM: $r=-0.113, p=0.616$; WM: $r=0.003, p=0.991$ ). According to the Fisher $r$-to- $z$ transformation, this correlation was significantly different between young and older adults $(z=$ $-2.16, p=0.031)$. There were no other significant correlations (all $p$ values $\geq 0.077$ ).

\section{Discussion}

The present study is the first to investigate the relationship between $\mathrm{GABA}^{+}$levels in a network consisting of cortical and subcortical regions known to be involved in motor inhibition and reactive/proactive inhibition efficiency in young and older adults. As expected, we found that older adults demonstrated performance decrements in reactive inhibition, whereas proactive inhibition was intact. $\mathrm{GABA}^{+}$levels within the different regions of the cortico-subcortical network were generally lower in older adults compared with young adults. However, our results suggest that specifically $\mathrm{GABA}^{+}$levels in the pre-SMA were related to the efficiency of reactive inhibition in older adults.

An anticipated response version of the stop-signal task with manipulation of stop-signal probability was used to measure reactive and proactive inhibition. The latency of the stop process (SSRT) was longer in older than young adults, indicating that reactive inhibition becomes less efficient with aging. This result is in agreement with the findings of previous studies (Williams et al., 1999; Bedard et al., 2002; Smittenaar et al., 2015; Bloemendaal et al., 2016; Coxon et al., 2016; Kleerekooper et al., 2016; Hsieh and Lin, 2017). In contrast, we did not find an age-related effect on proactive inhibition. Both young and older adults slowed down their response to the go signal when the probability of stopping increased. The absence of an age effect is in line with the findings of most studies (Smittenaar et al., 2015; Bloemendaal et al., 2016; Kleerekooper et al., 2016; Hsieh and Lin, 2017), although one study reported that proactive slowing was even more pronounced in older adults (van de Laar et al., 2011).

Consistent with results of previous MRS studies (Gao et al., 2013; Porges et al., 2017a), GABA ${ }^{+}$levels were on average lower in older adults compared with young adults. Nonetheless, one needs to be cautious when comparing MRS results across studies of healthy aging because different tissue correction methods have been used. As a consequence of agerelated brain atrophy, it is important to account for age-related differences in voxel composition when estimating GABA. Recent studies have shown that the results change as a function of the applied tissue correction method (Porges et al., 2017b). More specifically, it was reported that there is no effect of age on $\mathrm{GABA}^{+}$levels in frontal and parietal regions (Porges et al., $2017 \mathrm{~b}$ ) when the $\alpha$ correction was used (Harris et al., 2015a). The $\alpha$ correction includes the following: (1) the assumption that $\mathrm{GABA}^{+}$levels are twice as high in GM compared with WM; and (2) the normalization of $\mathrm{GABA}^{+}$levels to the group average voxel composition. This correction makes it less likely that differences in GABA levels are solely driven by interparticipant differences in voxel composition. We found that $\mathrm{GABA}^{+}$levels were on average lower in older adults compared with young adults when applying the $\alpha$ correction separately for the two groups. Furthermore, the age-related effect on GABA was still present when data quality measures were included in the statistical analysis, which indicates that this effect cannot be explained by group differences in head movement during scans. Interestingly, the amount of GABA ${ }^{+}$ differed across brain regions in young and older adults. This suggests that there are regional differences in $\mathrm{GABA}^{+}$levels, corroborating previous findings (Greenhouse et al., 2016).

It is not clear which processes may underlie the observed agerelated changes in $\mathrm{GABA}^{+}$levels. Possibly, these changes are driven by altered production of GABA. Evidence for this notion is provided by animal studies that have documented an age-related decrease in glutamic acid decarboxylase, an enzyme that is important for synthesizing GABA (Ling et al., 2005; Burianova et al., 2009). It has also been shown that the percentage of GABAergic neurons in the striate visual cortex of cats decreases as a function of age (Hua et al., 2008). The loss of GABAergic inhibitory interneurons might explain a decline in $\mathrm{GABA}^{+}$levels. However, this is highly speculative and requires further investigation.

Neuroimaging studies have shown that motor inhibition relies on an interaction among the RIFC, pre-SMA, and the basal ganglia (STN and/or striatum; Aron and Poldrack, 2006; Aron, 2007; Chambers et al., 2009; Coxon et al., 2016). Where the STN seems to be essential for reactive inhibition, the striatum may play a greater role in proactive inhibition (Vink et al., 2005; Zandbelt and Vink, 2010; Jahfari et al., 2011; Majid et al., 2013; Zand- 
belt et al., 2013; Leunissen et al., 2016). Moreover, several studies suggest that the GABA system plays an important role in response inhibition (Coxon et al., 2006; Silveri et al., 2013; Quetscher et al., 2015). Along these lines, we hypothesized that $\mathrm{GABA}^{+}$levels within the pre-SMA, RIFC, and LSM1 would correlate with inhibitory proficiency in general, while striatal GABA might predict proactive inhibition efficiency more specifically. The STN was not included due to its small size. In young adults, however, we did not observe a relationship between $\mathrm{GABA}^{+}$and behavior. In agreement, one study (Boy et al., 2010) that measured GABA ${ }^{+}$ in a similar region (SMA) did not find a correlation with SSRT in young adults. In contrast, our results showed that $\mathrm{GABA}^{+}$levels in the voxel centered over the pre-SMA were negatively correlated with the latency of the stop process in older adults. This relationship might become apparent only when GABAergic function is more variable. Even though not formally tested, this suggestion would fit with the observation that several patient groups with clear response inhibition impairments, such as attentiondeficit/hyperactivity disorder and Tourette's syndrome, also show alterations in GABAergic functioning (Edden et al., 2012; Puts et al., 2015).

The observed correlation in older adults fits with a large body of evidence that implicates the pre-SMA in motor inhibition. Patients with lesions to the SMA or pre-SMA have motor inhibition impairments (Floden and Stuss, 2006; Picton et al., 2007). Disruptive TMS delivered over the pre-SMA lengthens the SSRT (Chen et al., 2009; Cai et al., 2012). Neuroimaging studies reported increased activity in pre-SMA during successful stopping in young adults (Aron and Poldrack, 2006; Swick et al., 2011; Coxon et al., 2016), while hypoactivity has been observed in older adults (Coxon et al., 2016). The results of our study suggest that GABAergic inhibitory processes might (in part) underlie the role of the pre-SMA in the efficiency of reactive inhibition.

One limitation of the present study is the contribution of macromolecules to the GABA signal. Given that macromolecules have been shown to increase with aging (Marjańska et al., 2018), the effect of age on GABA might be underestimated in the present study.

In summary, we found that $\mathrm{GABA}^{+}$levels in both cortical and subcortical regions were lower in older adults compared with young adults. Moreover, pre-SMA GABA ${ }^{+}$levels were predictive for reactive inhibition performance in older adults. The structural network mediating motor inhibition is well known, but less is known about the functional role of the regions that are part of this network. Our results suggest that GABAergic functioning in pre-SMA may partly contribute to the efficiency of reactive inhibition. Pharmacological interventions targeting the GABA system may ameliorate reactive inhibition impairments.

\section{References}

Aron AR (2007) The neural basis of inhibition in cognitive control. Neuroscientist 13:214-228. CrossRef Medline

Aron AR (2011) From reactive to proactive and selective control: developing a richer model for stopping inappropriate responses. Biol Psychiatry 69:e55-e68. CrossRef Medline

Aron AR, Poldrack RA (2006) Cortical and subcortical contributions to stop signal response inhibition: role of the subthalamic nucleus. J Neurosci 26:2424-2433. CrossRef Medline

Bedard AC, Nichols S, Barbosa JA, Schachar R, Logan GD, Tannock R (2002) The development of selective inhibitory control across the life span. Dev Neuropsychol 21:93-111. CrossRef Medline

Behrens TE, Jenkinson M, Robson MD, Smith SM, Johansen-Berg H (2006) A consistent relationship between local white matter architecture and functional specialisation in medial frontal cortex. Neuroimage 30:220227. CrossRef Medline
Bloemendaal M, Zandbelt B, Wegman J, van de Rest O, Cools R, Aarts E (2016) Contrasting neural effects of aging on proactive and reactive response inhibition. Neurobiol Aging 46:96-106. CrossRef Medline

Boy F, Evans CJ, Edden RA, Singh KD, Husain M, Sumner P (2010) Individual differences in subconscious motor control predicted by GABA concentration in SMA. Curr Biol 20:1779-1785. CrossRef Medline

Burianova J, Ouda L, Profant O, Syka J (2009) Age-related changes in GAD levels in the central auditory system of the rat. Exp Gerontol 44:161-169. CrossRef Medline

Cai W, George JS, Verbruggen F, Chambers CD, Aron AR (2012) The role of the right pre-supplementary motor area in stopping action: two studies with event-related transcranial magnetic stimulation. J Neurophysiol 108: 380-389. CrossRef Medline

Chambers CD, Garavan H, Bellgrove MA (2009) Insights into the neural basis of response inhibition from cognitive and clinical neuroscience. Neurosci Biobehav Rev 33:631-646. CrossRef Medline

Chen CY, Muggleton NG, Tzeng OJ, Hung DL, Juan CH (2009) Control of prepotent responses by the superior medial frontal cortex. Neuroimage 44:537-545. CrossRef Medline

Coxon JP, Stinear CM, Byblow WD (2006) Intracortical inhibition during volitional inhibition of prepared action. J Neurophysiol 95:3371-3383. CrossRef Medline

Coxon JP, Stinear CM, Byblow WD (2007) Selective inhibition of movement. J Neurophysiol 97:2480-2489. CrossRef Medline

Coxon JP, Goble DJ, Leunissen I, Van Impe A, Wenderoth N, Swinnen SP (2016) Functional brain activation associated with inhibitory control deficits in older adults. Cereb Cortex 26:12-22. CrossRef Medline

Edden RA, Crocetti D, Zhu H, Gilbert DL, Mostofsky SH (2012) Reduced GABA concentration in attention-deficit/hyperactivity disorder. Arch Gen Psychiatry 69:750-753. CrossRef Medline

Edden RA, Puts NA, Harris AD, Barker PB, Evans CJ (2014) Gannet: a batch-processing tool for the quantitative analysis of gamma-aminobutyric acid-edited MR spectroscopy spectra. J Magn Reson Imaging 40: 1445-1452. CrossRef Medline

Edden RA, Oeltzschner G, Harris AD, Puts NA, Chan KL, Boer VO, Schär M, Barker PB (2016) Prospective frequency correction for macromoleculesuppressed GABA editing at 3T. J Magn Reson Imaging 44:1474-1482. CrossRef Medline

Floden D, Stuss DT (2006) Inhibitory control is slowed in patients with right superior medial frontal damage. J Cogn Neurosci 18:1843-1849. CrossRef Medline

Gao F, Edden RA, Li M, Puts NA, Wang G, Liu C, Zhao B, Wang H, Bai X, Zhao C, Wang X, Barker PB (2013) Edited magnetic resonance spectroscopy detects an age-related decline in brain GABA levels. Neuroimage 78:75-82. CrossRef Medline

Greenhouse I, Noah S, Maddock RJ, Ivry RB (2016) Individual differences in GABA content are reliable but are not uniform across the human cortex. Neuroimage 139:1-7. CrossRef Medline

Harris AD, Puts NA, Edden RA (2015a) Tissue correction for GABA-edited MRS: considerations of voxel composition, tissue segmentation, and tissue relaxations. J Magn Reson Imaging 42:1431-1440. CrossRef Medline

Harris AD, Puts NA, Barker PB, Edden RA (2015b) Spectral-editing measurements of GABA in the human brain with and without macromolecule suppression. Magn Reson Med 74:1523-1529. CrossRef Medline

Hsieh S, Lin YC (2017) Stopping ability in younger and older adults: behavioral and event-related potential. Cogn Affect Behav Neurosci 17:348363. CrossRef Medline

Hua T, Kao C, Sun Q, Li X, Zhou Y (2008) Decreased proportion of GABA neurons accompanies age-related degradation of neuronal function in cat striate cortex. Brain Res Bull 75:119-125. CrossRef Medline

Jahanshahi M, Obeso I, Rothwell JC, Obeso JA (2015) A fronto-striatosubthalamic-pallidal network for goal-directed and habitual inhibition. Nat Rev Neurosci 16:719-732. CrossRef Medline

Jahfari S, Waldorp L, van den Wildenberg WP, Scholte HS, Ridderinkhof KR, Forstmann BU (2011) Effective connectivity reveals important roles for both the hyperdirect (fronto-subthalamic) and the indirect (frontostriatal-pallidal) fronto-basal ganglia pathways during response inhibition. J Neurosci 31:6891-6899. CrossRef Medline

Kim JH, Lee JM, Jo HJ, Kim SH, Lee JH, Kim ST, Seo SW, Cox RW, Na DL, Kim SI, Saad ZS (2010) Defining functional SMA and pre-SMA subregions in human MFC using resting state fMRI: functional connectivity-based parcellation method. Neuroimage 49:2375-2386. CrossRef Medline 
Kleerekooper I, van Rooij SJH, van den Wildenberg WPM, de Leeuw M, Kahn RS, Vink M (2016) The effect of aging on fronto-striatal reactive and proactive inhibitory control. Neuroimage 132:51-58. CrossRef Medline

Leunissen I, Coxon JP, Swinnen SP (2016) A proactive task set influences how response inhibition is implemented in the basal ganglia. Hum Brain Mapp 37:4706-4717. CrossRef Medline

Levin O, Fujiyama H, Boisgontier MP, Swinnen SP, Summers JJ (2014) Aging and motor inhibition: a converging perspective provided by brain stimulation and imaging approaches. Neurosci Biobehav Rev 43:100117. CrossRef Medline

Ling LL, Hughes LF, Caspary DM (2005) Age-related loss of the GABA synthetic enzyme glutamic acid decarboxylase in rat primary auditory cortex. Neuroscience 132:1103-1113. CrossRef Medline

Logan GD, Cowan WB (1984) On the ability to inhibit thought and action: a theory of an act of control. Psychol Rev 91:295-327. CrossRef

Majid DS, Cai W, Corey-Bloom J, Aron AR (2013) Proactive selective response suppression is implemented via the basal ganglia. J Neurosci 33: 13259-13269. CrossRef Medline

Marjańska M, Deelchand DK, Hodges JS, McCarten JR, Hemmy LS, Grant A, Terpstra M (2018) Altered macromolecular pattern and content in the aging human brain. NMR Biomed 31:e3865. CrossRef Medline

Mescher M, Merkle H, Kirsch J, Garwood M, Gruetter R (1998) Simultaneous in vivo spectral editing and water suppression. NMR Biomed 11:266272. CrossRef Medline

Mikkelsen M, Singh KD, Sumner P, Evans CJ (2016) Comparison of the repeatability of GABA-edited magnetic resonance spectroscopy with and without macromolecule suppression. Magn Reson Med 75:946-953. CrossRef Medline

Mikkelsen M, Barker PB, Bhattacharyya PK, Brix MK, Buur PF, Cecil KM, Chan KL, Chen DY, Craven AR, Cuypers K, Dacko M, Duncan NW, Dydak U, Edmondson DA, Ende G, Ersland L, Gao F, Greenhouse I, Harris AD, He N, et al (2017) Big GABA: edited MR spectroscopy at 24 research sites. Neuroimage 159:32-45. CrossRef Medline

Mullins PG, McGonigle DJ, O'Gorman RL, Puts NA, Vidyasagar R, Evans CJ, Edden RA (2014) Current practice in the use of MEGA-PRESS spectroscopy for the detection of GABA. Neuroimage 86:43-52. CrossRef Medline

Near J, Edden R, Evans CJ, Paquin R, Harris A, Jezzard P (2015) Frequency and phase drift correction of magnetic resonance spectroscopy data by spectral registration in the time domain. Magn Reson Med 73:44-50. CrossRef Medline

Picton TW, Stuss DT, Alexander MP, Shallice T, Binns MA, Gillingham S (2007) Effects of focal frontal lesions on response inhibition. Cereb Cortex 17:826-838. CrossRef Medline

Porges EC, Woods AJ, Edden RA, Puts NA, Harris AD, Chen H, Garcia AM, Seider TR, Lamb DG, Williamson JB, Cohen RA (2017a) Frontal gamma-aminobutyric acid concentrations are associated with cognitive performance in older adults. Biol Psychiatry Cogn Neurosci Neuroimaging 2:38-44. CrossRef Medline

Porges EC, Woods AJ, Lamb DG, Williamson JB, Cohen RA, Edden RAE, Harris AD (2017b) Impact of tissue correction strategy on GABA-edited MRS findings. Neuroimage 162:249-256. CrossRef Medline

Puts NA, Edden RA (2012) In vivo magnetic resonance spectroscopy of
GABA: a methodological review. Prog Nucl Magn Reson Spectrosc 60: 29-41. CrossRef Medline

Puts NA, Edden RA, Evans CJ, McGlone F, McGonigle DJ (2011) Regionally specific human GABA concentration correlates with tactile discrimination thresholds. J Neurosci 31:16556-16560. CrossRef Medline

Puts NAJ, Harris AD, Crocetti D, Nettles C, Singer HS, Tommerdahl M, Edden RA, Mostofsky SH (2015) Reduced GABAergic inhibition and abnormal sensory symptoms in children with Tourette syndrome. J Neurophysiol 114:808-817. CrossRef Medline

Quetscher C, Yildiz A, Dharmadhikari S, Glaubitz B, Schmidt-Wilcke T, Dydak U, Beste C (2015) Striatal GABA-MRS predicts response inhibition performance and its cortical electrophysiological correlates. Brain Struct Funct 220:3555-3564. CrossRef Medline

Rothman DL, Petroff OA, Behar KL, Mattson RH (1993) Localized 1H NMR measurements of gamma-aminobutyric acid in human brain in vivo. Proc Natl Acad Sci U S A 90:5662-5666. CrossRef Medline

Silveri MM, Sneider JT, Crowley DJ, Covell MJ, Acharya D, Rosso IM, Jensen JE (2013) Frontal lobe gamma-aminobutyric acid levels during adolescence: associations with impulsivity and response inhibition. Biol Psychiatry 74:296-304. CrossRef Medline

Smittenaar P, Rutledge RB, Zeidman P, Adams RA, Brown H, Lewis G, Dolan RJ (2015) Proactive and reactive response inhibition across the lifespan. PLoS One 10:e0140383. CrossRef Medline

Swick D, Ashley V, Turken U (2011) Are the neural correlates of stopping and not going identical? quantitative meta-analysis of two response inhibition tasks. Neuroimage 56:1655-1665. CrossRef Medline

van de Laar MC, van den Wildenberg WP, van Boxtel GJ, van der Molen MW (2011) Lifespan changes in global and selective stopping and performance adjustments. Front Psychol 2:357. CrossRef Medline

van den Wildenberg WP, Burle B, Vidal F, van der Molen MW, Ridderinkhof KR, Hasbroucq T (2010) Mechanisms and dynamics of cortical motor inhibition in the stop-signal paradigm: a TMS study. J Cogn Neurosci 22:225-239. CrossRef Medline

Verbruggen F, Logan GD (2009) Models of response inhibition in the stopsignal and stop-change paradigms. Neurosci Biobehav Rev 33:647-661. CrossRef Medline

Vink M, Kahn RS, Raemaekers M, van den Heuvel M, Boersma M, Ramsey NF (2005) Function of striatum beyond inhibition and execution of motor responses. Hum Brain Mapp 25:336-344. CrossRef Medline

Wessel JR, Reynoso HS, Aron AR (2013) Saccade suppression exerts global effects on the motor system. J Neurophysiol 110:883-890. CrossRef Medline

Williams BR, Ponesse JS, Schachar RJ, Logan GD, Tannock R (1999) Development of inhibitory control across the life span. Dev Neuropsychol 35: 205-213. CrossRef Medline

Yousry TA, Schmid UD, Alkadhi H, Schmidt D, Peraud A, Buettner A, Winkler P (1997) Localization of the motor hand area to a knob on the precentral gyrus. A new landmark. Brain 120:141-157. CrossRef Medline

Zandbelt BB, Vink M (2010) On the role of the striatum in response inhibition. PLoS One 5:e13848. CrossRef Medline

Zandbelt BB, Bloemendaal M, Neggers SF, Kahn RS, Vink M (2013) Expectations and violations: delineating the neural network of proactive inhibitory control. Hum Brain Mapp 34:2015-2024. CrossRef Medline 